\title{
Development of HTS Conductors for Fusion Magnets
}

\author{
D. Uglietti, N. Bykovsky, R. Wesche, P. Bruzzone
}

\begin{abstract}
In view of the development of cables for next generation Fusion Reactors research activities are carried out on all HTS materials available from industrial production. Preliminary design of a react and wind cable using Bi2212 wires is carried out, inspired by the $\mathrm{Nb}_{3} \mathrm{Sn}$ cable for European DEMO. The design and construction of a $60 \mathrm{kA}$ prototype cable made of coated conductors have been carried out. The strands in the cable are composed of a stack of coated conductor tapes ( $4 \mathrm{~mm}$ wide) embedded in a copper profile of $6.3 \mathrm{~mm}$ in diameter. Tapes and copper profiles are soldered together in order to obtain a mechanically solid strand and to keep the inter tape resistance at minimum, so that current can be easily redistributed among the tapes in a strand. The strands are fabricated in pieces $2 \mathrm{~m}$ long, but scaling up to industrial production should not present any major problem. A flat cable is manufactured by winding twenty strands around a central copper former; the cable will be inserted in a steel jacket for force flow cooling. The critical current of each strand was measured at liquid nitrogen in self field just after the manufacturing process (twisted and straight) and after cabling: no reduction of the critical current was observed. Two pieces of cable each $2 \mathrm{~m}$ long are going to be prepared and assembled to form a sample that can be tested in the EDIPO facility.
\end{abstract}

Index Terms-HTS cable, coated conductor, BSCCO, REBCO, Bi2212, Bi2223, fusion magnet, fusion cable.

\section{INTRODUCTION}

$\mathrm{T}$ HE construction of the ITER fusion reactor is progressing and the completion of the machine is scheduled for 2019. In Europe the R\&D phase for the next generation of fusion reactors (DEMO), which are supposed to prove the generation of the electricity at an affordable price, is just started [1]. The use of High Temperature Superconducting (HTS) materials is not excluded a priori, even if the most reliable and mature option is to use a graded $\mathrm{NbTi} / \mathrm{Nb}_{3} \mathrm{Sn}$ coil [2]. There are various motivations for using HTS materials in fusion magnets [3], which in turn depend on the way the HTS material is integrated in the magnet system. If the price of the HTS cable is comparable to the one of the $\mathrm{Nb}_{3} \mathrm{Sn}$ cable, one can imagine a graded coil with LTS and HTS sections, both operated at $5 \mathrm{~K}$; in this case one motivation for using HTS material could be the larger temperature margin in the coil section more exposed to nuclear heating; indeed a large temperature margin could be an advantage for the cryogenic and cooling system. Another motivation could be the fact that the HTS section is more compact, which would save space for the blanket, as it was proposed in [4].

Automatically generated dates of receipt and acceptance will be placed here. (Corresponding author: D. Uglietti.)

D. Uglietti, R. Wesche and P. Bruzzone are with EPFL-CRPP, Fusion Technology, CH-5232 Villigen PSI, e-mail: davide.uglietti@psi.ch.
If the price of HTS materials gets sufficiently low (i.e. at least lower than the price of $\mathrm{Nb}_{3} \mathrm{Sn}$ ) it could be economically more convenient to make a full HTS magnet system, which may be still operated at $5 \mathrm{~K}$; if the cost gets much lower than the one of $\mathrm{Nb}_{3} \mathrm{Sn}$ and the in-field critical current at high temperatures is improved, it would be possible to exploit the most striking advantage of HTS materials, namely the possibility to operate at fields and temperatures not accessible to LTS materials. As an example of this use, a magnet system with Bi2212 cables operated at $20 \mathrm{~K}$ and $20 \mathrm{~T}$ was proposed in [5], even if the operating conditions were unrealistic.

At the Center for Research on Plasma Physics (CRPP) the main activity is designing, building and testing prototype cables for fusion magnets, with operating currents up to $100 \mathrm{kA}$, i.e. suitable for ITER or DEMO type reactors. This paper is mainly focused on the construction of a short prototype cable using coated conductor tape (REBCO). Preliminary designs of HTS cables for DEMO type magnets are also presented; all the HTS materials have been considered: REBCO tapes, Bi2212 wires and Bi2223 tapes.

\section{BI2212 CABLE DESIGN}

Even if Bi2212 was one of the first HTS materials to come on the market, the relative low critical current density and the difficulties in manufacturing coils with long length of wires have prevented the use in applications. Recently a new over-pressure heat treatment [6] has allowed obtaining much higher critical current density and improving the reliability of the coil construction. Despite the improvement, the critical current in field is still strongly reduced at high temperatures, and Bi2212 is not suitable for operation at temperatures much higher than $15 \mathrm{~K}$ : indeed Bi2212 should be considered a high field superconductor rather than a high temperature superconductor.

The application of Bi2212 wires for a fusion magnet was first proposed more than 10 years ago. In [7] a prototype cable (round cable composed of 729 strand, each $0.8 \mathrm{~mm}$ in diameter) could carry $10 \mathrm{kA}$ at $20 \mathrm{~K}$ and $12 \mathrm{~T}$. In [5] the design of a magnet system using only Bi2212 was carried out, but the envisaged operating conditions were an astonishing and unrealistic $20 \mathrm{~T}$ and $20 \mathrm{~K}$, at which even the present wires cannot provide sufficient current density. More recently [4] a graded magnet, consisting of an outer $\mathrm{Nb}_{3} \mathrm{Sn}$ section and an innermost Bi2212 section, was proposed for the future Chinese Thermonuclear Fusion Reactor (CFETR); the main reason to use Bi2212 cables for the innermost section was the compactness of the HTS section which would free up space for the blanket. Both papers mentioned above are mainly focused on the magnet system, lacking details on the Bi2212 
cable.

Despite $\mathrm{Bi} 2212$ is the cheapest of the HTS materials available on the market, the material cost of a Bi2212 cable for $\operatorname{DEMO}(5 \mathrm{~K}, 13.5 \mathrm{~T})$ is still more expensive than the one of $\mathrm{Nb}_{3} \mathrm{Sn}$ by a factor 2 to 5 . Only at fields higher than $16 \mathrm{~T}$ or $18 \mathrm{~T}$ the material cost of a Bi2212 cable becomes lower than the one of $\mathrm{Nb}_{3} \mathrm{Sn}$.

There are various similarities between $\mathrm{Bi} 2212$ wires and $\mathrm{Nb}_{3} \mathrm{Sn}$ wires: round wires with diameter from 0.6 to $1.5 \mathrm{~mm}$, high temperature reaction heat treatments and small variation (few $\%$ ) of $\mathrm{I}_{\mathrm{c}}$ over a narrow strain window (i.e. from $-0.2 \%$ to $+0.2 \%)$. Therefore one possibility is to adapt the React and Wind (R\&W) design proposed for the DEMO $\mathrm{Nb}_{3}$ Sn cable [2] to $\mathrm{Bi} 2212$ wires. In short, the $\mathrm{Nb}_{3} \mathrm{Sn}$ conductor for DEMO is composed of a flat cable assembled with 300 strands $(1.5 \mathrm{~mm}$ in diameter). The cable is reacted on a $7 \mathrm{~m}$ diameter former and, after the reaction, a steel jacket is welded around the cable. After winding the Toroidal Field (TF) coil, whose minimum bending radius is $3.5 \mathrm{~m}$, the strain state of the wires will be in the range comprised between $-0.08 \%$ and $+0.08 \%$. The reasons for choosing the $\mathrm{R} \& \mathrm{~W}$ technique are both technological and economic, as discussed in [2], and are still valid for a Bi2212 cable.

For the dimensioning (i.e. how much superconducting material is required) of a cable in conduit operated in forced flow cooling, it is important to point out that a sufficient temperature margin should be guaranteed. For example, in the $\mathrm{Nb}_{3} \mathrm{Sn}$ cable for DEMO the temperature margin at the operating conditions $(80 \mathrm{kA}, 5 \mathrm{~K}, 13.5 \mathrm{~T})$ is about $1.5 \mathrm{~K}$. A simple way to estimate the operating current is to plot the reduced critical current as a function of the temperature at the operating field $(13.5 \mathrm{~T})$, as shown in fig. 1a: the data are for a $\mathrm{Nb}_{3} \mathrm{Sn}$ strand for ITER. From fig. 1a it is clear that, if $1.5 \mathrm{~K}$ of temperature margin is required, the operating current at $13.5 \mathrm{~T}$ and $5 \mathrm{~K}$ should be only $65 \%$ of the corresponding critical current at $13.5 \mathrm{~T}$ and $5 \mathrm{~K}$.

The same type of plot is shown in fig. $1 \mathrm{~b}$ for a Bi2212 wire (data from [8]). The temperature dependence of the critical current is much flatter; it follows that even if the operating current is as high as $80 \%$ of the critical current (at $13.5 \mathrm{~T}$ and $5 \mathrm{~K}$ ), the temperature margin is almost $3 \mathrm{~K}$, i.e. twice larger than in the $\mathrm{Nb}_{3} \mathrm{Sn}$ cable. Therefore the critical current (at $13.5 \mathrm{~T}$ and $5 \mathrm{~K}$ ) of the cable could be about $100 \mathrm{kA}$ for an operating current of about $80 \mathrm{kA}$. Assuming an engineering current density of $500 \mathrm{~A} / \mathrm{mm}^{2}$ at $13.5 \mathrm{~T}$ and $5 \mathrm{~K}$, which is within the possibility of present industrial production, about 110 strand of $1.5 \mathrm{~mm}$ diameter will be needed to obtain a critical current of $100 \mathrm{kA}$. The 110 strands can be arranged in a two stages (7x16) flat cable, as shown in fig. 2 . The cable is compacted down to $25 \%$ of void fraction. The Bi2212 cable is wrapped by copper wires (about $600 \mathrm{~mm}^{2}$ of total cross section), which provide the protection in case of quench and make the handling easier and safer. A steel jacket with two cooling channels is welded around the cable as in the case of $\mathrm{Nb}_{3} \mathrm{Sn}$ cable. After reaction heat treatment and coil winding the strain state of the Bi2212 strands will be between $-0.07 \%$ and $+0.07 \%$. In the tensile region $(+0.07 \%) I_{c}$ would be reduced (reversibly) by less than $0.5 \%$, while in the compressive region $(-0.07 \%)$ the irreversible reduction of $\mathrm{I}_{\mathrm{c}}$ would be about $1 \%$ (values estimated from [9]).

The longitudinal electromagnetic load will be taken by the steel jacket; the only load acting directly on the cable is the

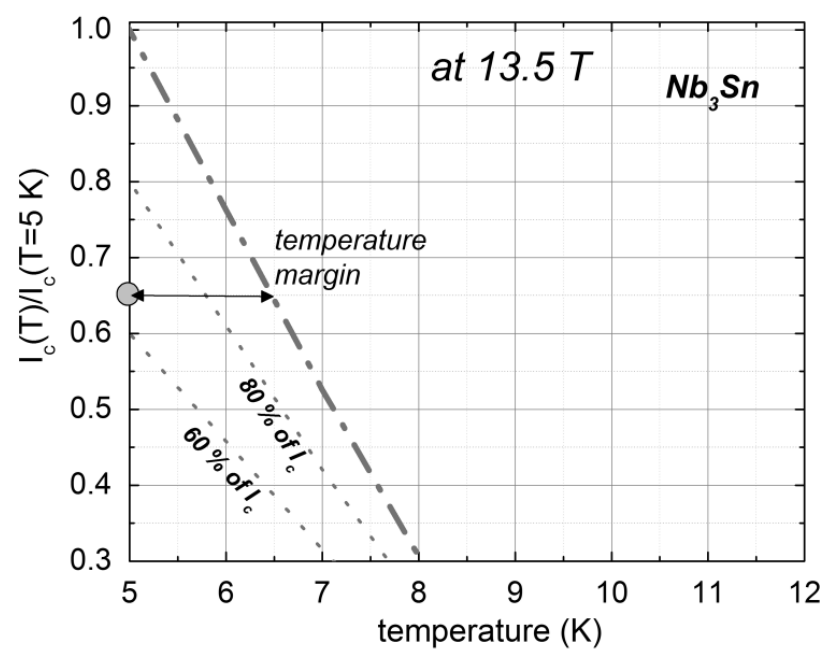

Fig. 1a. Reduced critical current versus temperature for an Internal $\mathrm{Sn} \mathrm{Nb}_{3} \mathrm{Sn}$ wire at $13.5 \mathrm{~T}$. The values corresponding to $80 \%$ and $60 \%$ of the critical current are plotted. The intrinsic strain was $-0.2 \%$.

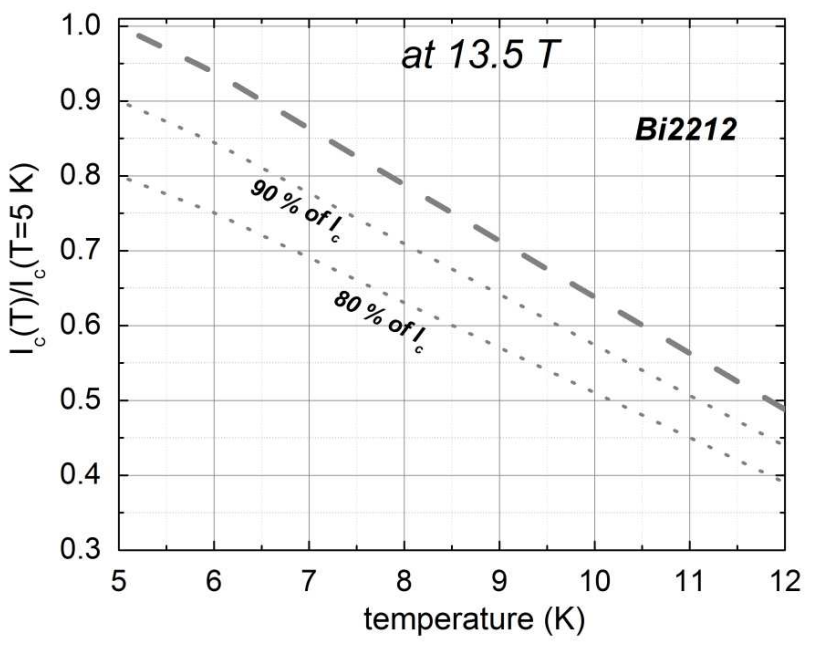

Fig. 1b. Reduced critical current versus temperature for a Bi2212 wire [8] at $13.5 \mathrm{~T}$. The values corresponding to $90 \%$ and $80 \%$ of the critical current are plotted.

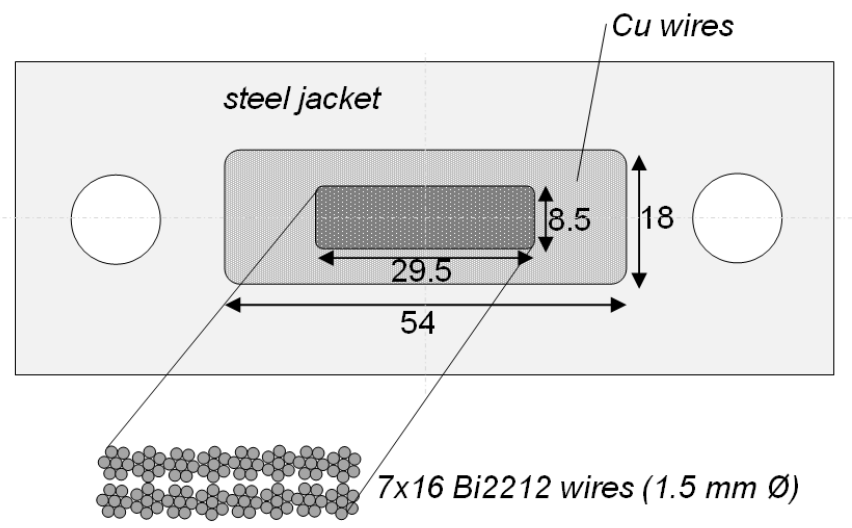

Fig. 2. Cross section of the Bi2212 cable for DEMO. It is composed of 7x16 $\mathrm{Bi} 2212$ wires $(\varnothing 1.5 \mathrm{~mm})$ and surrounded by copper wires for stabilization. A steel jacket with two channels for cooling is welded around the cable. 
electromagnetic transverse load. In the cable of fig.2 the transverse stress at operation $(80 \mathrm{kA}$ and $13.5 \mathrm{~T})$ would be about $35 \mathrm{MPa}$. This value is below the value of $50 \mathrm{MPa}$ reported for a $\mathrm{Bi} 2212$ Rutherford cable in [10] at which no reduction of the critical current was observed.

\section{PROTOTYPE COATED CONDUCTOR CABLE}

Coated conductors are the newcomer in the family of industrially produced HTS materials. In contrast with Bi2212, the superconducting ceramic phase is formed during the manufacturing of the tape. Therefore the main issue in preparing a cable with coated conductors is the accumulation of strain resulting from the strand fabrication, the cabling process and the winding of the final coil. The main advantages for fusion applications, with respect to $\mathrm{Bi} 2212$ wires and Bi2223 tapes, are the large strain window (up to $0.6 \%$ tensile strain), the potential of low cost production and the high critical current densities in field at temperature $>20 \mathrm{~K}$, due to the much higher irreversibility fields of REBCO than those of $\mathrm{Bi} 2212$ and $\mathrm{Bi} 2223$.

\section{A. Cable design}

In fig. 3 the reduced critical current versus temperature is plotted for a coated conductor tape (data from [8]) as a function of the temperature. In case of coated conductors the temperature dependence is even weaker than the one of Bi2212 wires (see fig. 1b). Therefore it could be possible to operate the cable at $90 \%$ of the critical current but still having $3 \mathrm{~K}$ of temperature margin. At an operating current of $80 \%$ the temperature margin will be $6 \mathrm{~K}$, four times larger than in the case of $\mathrm{Nb}_{3} \mathrm{Sn}$.

Various cabling method have been proposed in order to manufacture cables using tapes: stacked tapes in copper [11], Roebel cable [12], CORC cable [13], and round hollow wires, proposed by Nexans [14]. At CRPP a variation of the stacked tape concept was chosen [15]. The stack of tapes is sandwiched between two semicircular shells (called also copper profiles), twisted and soldered. By twisting the strand before soldering the strain on the superconducting layer is kept

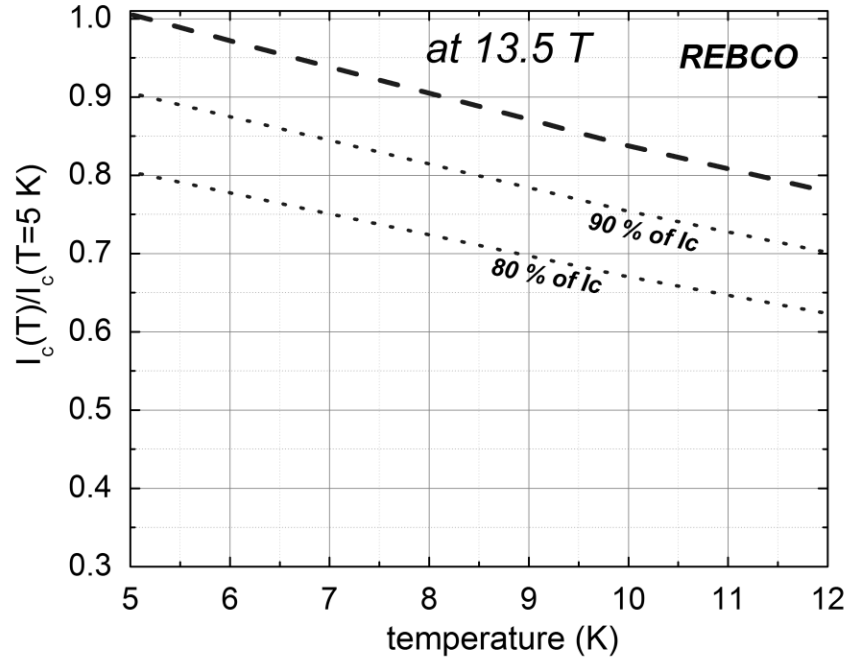

Fig. 3. Reduced critical current versus temperature for a REBCO tape [] at $13.5 \mathrm{~T}$. The values corresponding to $90 \%$ and $80 \%$ of the critical current are plotted. at a minimum. The soldering process is carried out in order to obtain a solid strand without voids and for ensuring a low inter-tape resistance, which helps current redistribution. The strands are then used to manufacture a flat cable, which can also be considered as a Rutherford cable with a flat copper core. The function of the copper core (it is $56 \mathrm{~mm}$ wide and $5 \mathrm{~mm}$ thick in the manufactured prototype cable) is to provide enough copper cross section for protection and to reduce the bending strain of the strands at the edges of the cable. In this prototype cable the bending radius of the strands at the cable edge is set at about $360 \mathrm{~mm}$, which is higher than the critical bending radius $(240 \mathrm{~mm})$.

The parameters of the cable, like the copper core dimensions and the cable twist pitch, have been selected so that enough copper is present in the cable while the strain due to the bending of the strands at the cable edges is minimized. The optimization of the cable parameters is discussed in detail in [14]. A schematic cross section of the cable under preparation is reported in fig. 4.

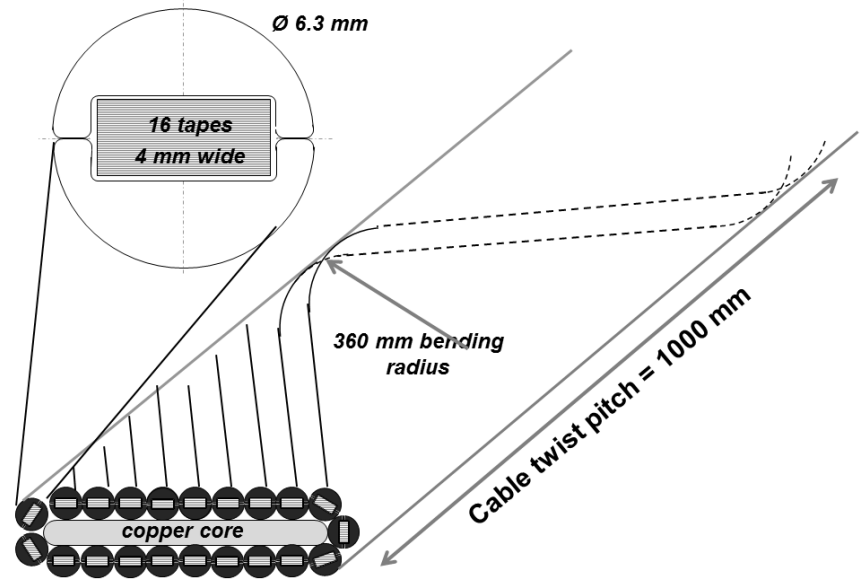

Fig. 4. Schematic cross section of the prototype cable made with coated conductors. The cable twist pitch is $1000 \mathrm{~mm}$, while the strand twist pitch is $320 \mathrm{~mm}$. The bending radius for the strands at the cable edge is $360 \mathrm{~mm}$.

\section{B. Cable construction}

A first prototype cable was manufactured using standard tape from Superpower (type SCS4050, $4 \mathrm{~mm}$ wide). First the tape was coated with eutectic $\mathrm{SnPb}$ solder by immersion in a bath of molten solder (temperature about $200^{\circ} \mathrm{C}$ ); a reel to reel process was used, with a speed of several $\mathrm{cm} / \mathrm{s}$; a colophonium solution was used as flux to improve the wettability of the solder.

The semicircular copper profiles were delivered by Precimet SA in pieces $3 \mathrm{~m}$ long; continuous production is also possible. The profiles were produced by cold rolling, which induced a relative large cold work hardening. Therefore an annealing heat treatment at $200^{\circ} \mathrm{C}$ for about 30 minutes was used to soften the copper (re-crystallization heat treatment). There were two reasons to apply the annealing heat treatment: first, the cabling is easier at laboratory scale, because the annealed strands are softer and easier to deform plastically. Second, it was observed (see [16] for details) that in the strands made with non-annealed copper the soldering between the two semicircular profiles breaks at relatively large bending 
radius. Instead the strands made with annealed copper profiles could be bent to smaller bending radius without breakage of the soldering connection. After annealing the copper profiles were coated with eutectic $\mathrm{SnPb}$ solder.

Twenty strands, each $2 \mathrm{~m}$ long and $6.3 \mathrm{~mm}$ in diameter, were assembled by stacking 16 tapes between two copper profiles (in total 320 tapes are present in the cable); each strand was kept together using short pieces of plastic tubes. After the assembling, the strands were twisted $(320 \mathrm{~mm}$ twist pitch) by clamping the strand between two chucks about $1800 \mathrm{~mm}$ apart: one was kept fixed while the other was rotated till the desired twist pitch is reached. The twisted strands are soldered by immersion in a bath of molten solder (continuous process). The industrialization of this process for continuous production (several kilometers) should not present major technical challenges. Assembling and twisting could be carried out in line: the strand would be wrapped with a wire or tape in order to keep all the elements together (instead of the plastic tube) and twisting could be applied by a rotating pickup spool.

Because of the short length of the prototype cable ( 2 meters) the cabling process was carried out entirely by hand. The strands were placed on the copper core one by one, using several small clamps to keep the strands in position. The annealed soft copper was easily bent by hand without much force. Despite the difference in bending stiffness (due to the

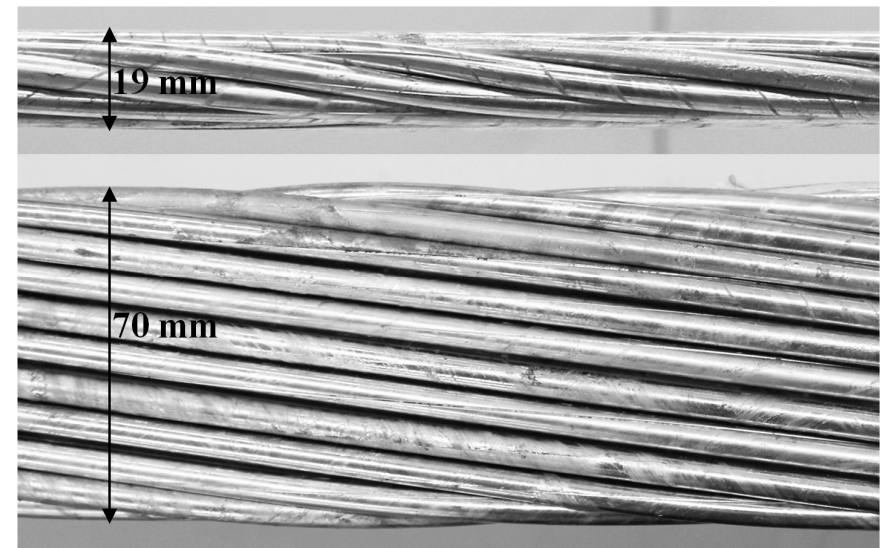

Fig. 5. View of the prototype cable made with REBCO tape, from the edge (top) and from the wide side (bottom).

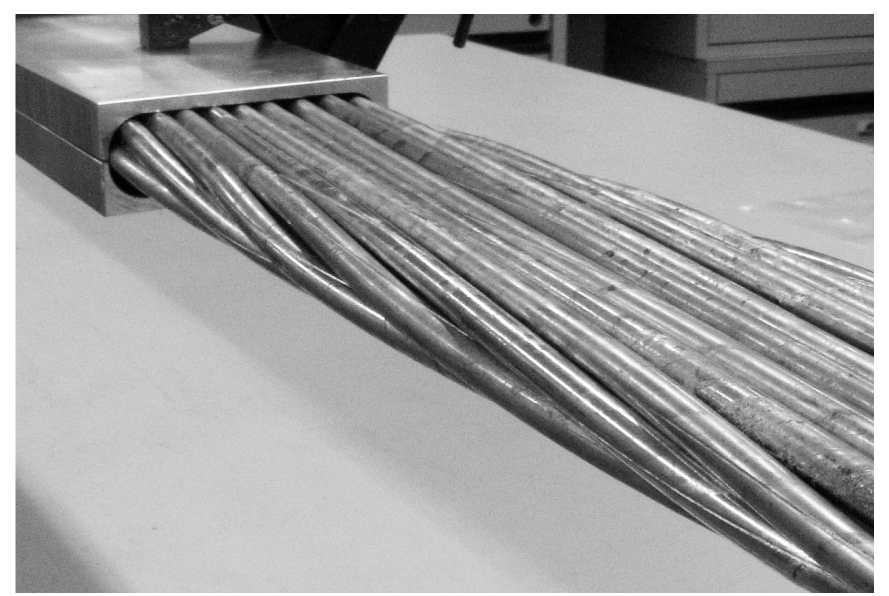

Fig. 6. Picture of the prototype cable prepared at CRPP. The jacket is a mock up made of aluminum. difference between hard and easy bending for the stack of tapes), the cable dimensions were rather uniform along the length. Photographs of the cable taken from the wide side and from the edge are shown in fig. 5. A steel jacket will be welded around the cable; an aluminum mockup of the jacket is shown in fig. 6 . The supercritical helium will flow in the space between the strands and the jacket.

A second cable section identical in size to the first cable is in preparation with tapes from Superox; the two cable sections will be assembled together, so that they can be tested in SULTAN or EDIPO facilities, where currents up to $100 \mathrm{kA}$ are supplied by a superconducting transformer. The operation at such high current is possible only if the resistance of the circuit connecting the superconducting transformer with the two cables is lower than few nano-ohms. For this reason particular care is taken in the design of the terminations.

At the ends of each strand the tapes are cut longer than the copper profiles and they have been staggered, so that every tape has about $15 \mathrm{~mm}$ of the side in correspondence with the ceramic layer exposed (i.e. not covered by other tapes). The tape orientation at both ends of each strand is the same, because the sample length is exactly 6 times longer than the strand twist pitches. Small deviations have been corrected using a hand tool. The staggered ends at each end of the cable will be inserted and soldered in copper blocks, in which rectangular grooves have been machined; the copper blocks are the current terminations for the cables. In this way every tapes has the ceramic side (over $15 \mathrm{~mm}$ ) in direct contact with the copper block terminals.

\section{Preliminary test at $77 \mathrm{~K}$}

All the strands were measured at $77 \mathrm{~K}$ after the fabrication process (i.e. the strands were twisted and soldered and measured straight): the range of critical current was between $1050 \mathrm{~A}$ and $1150 \mathrm{~A}$ in self field, while the $n$ value was between 20 and 25. Seven strands were also measured after the cabling process, i.e. after they were put in the cable (bending at the cable edges). As it was expected from a test on a short strand [16], no reduction of the critical current was observed for these seven strands; also the $n$ value was not reduced. The critical current of more than half of the tape employed for the construction of the cable was measured at $4.2 \mathrm{~K}$ and $12 \mathrm{~T}$; from these measurements the critical current of the cable is estimated to be between $57 \mathrm{kA}$ and $61 \mathrm{kA}$ (at $4.2 \mathrm{~K}$ and $12 \mathrm{~T}$ ).

\section{Design of a DEMO class cable}

Based on the experience accumulated in the development of the prototype cable described above, two possible layouts for a DEMO class cable (operating currents of about $80 \mathrm{kA}$, corresponding to a critical current of $100 \mathrm{kA}$ at $5 \mathrm{~K}$ and $13.5 \mathrm{~T}$ ) are proposed (see fig. 7). In order to accommodate a larger number of tapes, it could be possible to change the aspect ratio of the stack from rectangular to square: for example 34 tapes $4 \mathrm{~mm}$ wide, or 24 tapes each $3 \mathrm{~mm}$ wide. The stack with $4 \mathrm{~mm}$ wide tape could be stacked and assembled in a strand of $7.8 \mathrm{~mm}$ in diameter and the final 
TABLE I

MAIN PROPERTIES OF CABLES FOR FUSION MAGNETS

\begin{tabular}{lcccc}
\hline \hline \multicolumn{1}{c}{ name } & $\begin{array}{c}\text { Cu cross } \\
\text { section }\end{array}$ & $\begin{array}{c}\text { Operating } \\
\text { current }\end{array}$ & Temperature margin & Status \\
\hline $\mathrm{TF} \mathrm{cable}\left(\mathrm{Nb}_{3} \mathrm{Sn}\right)-$ ITER & $513 \mathrm{~mm}^{2}$ & $68 \mathrm{kA}$ & $0.7 \mathrm{~K}$ & Cables in construction since 2012 \\
$\mathrm{Nb}_{3} \mathrm{Sn}$ - DEMO & $688 \mathrm{~mm}^{2}$ & $82 \mathrm{kA}$ & $1.5 \mathrm{~K}$ & Prototype in construction [2], test planned in 2015 \\
$\mathrm{REBCO}-$ DEMO & $560 \mathrm{~mm}^{2}$ & $80 \mathrm{kA}$ & $3 \mathrm{~K}$ to $6 \mathrm{~K}$ & Preliminary design completed (this work) \\
$\mathrm{Bi2} 212$ - DEMO & $600 \mathrm{~mm}^{2}$ & $80 \mathrm{kA}$ & $3 \mathrm{~K}$ & Preliminary design completed (this work) \\
REBCO prototype & $790 \mathrm{~mm}^{2}$ & $50 \mathrm{kA}$ & $6 \mathrm{~K}$ & Prototype in construction (this work), test planned within 2014 \\
\hline \hline
\end{tabular}

cable will be made with 16 of these strands. In this case the core of the cable could be made of steel instead of copper, because the copper cross section in the strands $\left(680 \mathrm{~mm}^{2}\right)$ is enough to protect the magnet during a quench. The stack with $3 \mathrm{~mm}$ wide tape could be stacked and assembled in a strand of $6.1 \mathrm{~mm}$ in diameter and the final cable will be made with 26 of these strands. A schematic cross section of the two designs is reported in fig. 7. With the continuous improvement of the critical current density, it is expected that the total number of tapes required could be further decreased, resulting in a smaller number of strands. The manufacturing and test of two short samples $(50 \mathrm{~cm})$ of the two types of strands is under way. A summary of the cable for fusion magnets described in this work is presented in Table I.
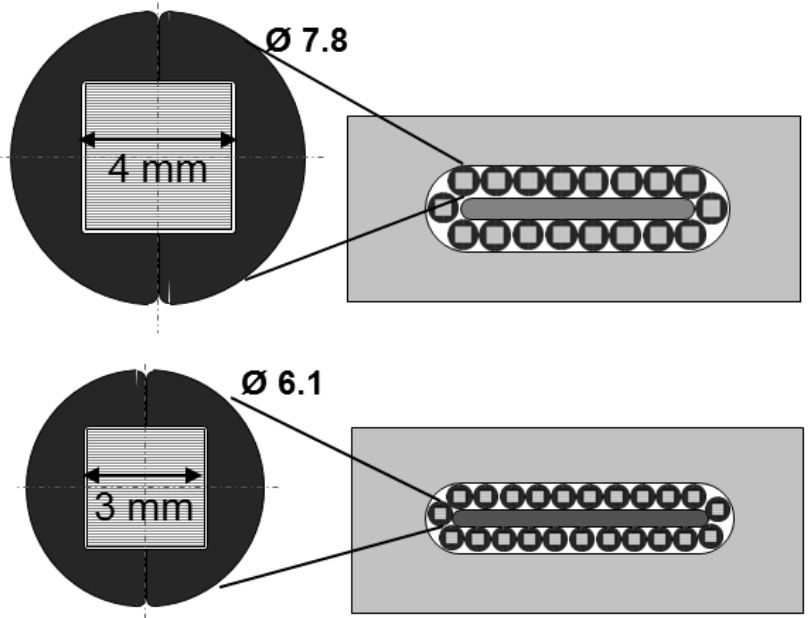

Fig. 7. Schematic cross sections of two possible DEMO type cables made with coated conductor tape. Top: option with $4 \mathrm{~mm}$ wide tape (cable core is made with steel). Bottom: option with $4 \mathrm{~mm}$ wide tape (cable core is made with copper)

\section{BI2223 CABLE: STRAND CONSTRUCTION TRIAL}

Similar to coated conductor, the Bi2223 tapes with silver sheath can be stacked and soldered between two copper half round profiles, but in contrast to coated conductors the maximum tensile strain is limited to $0.25 \%$.

The Bi2223 tape from Sumitomo (DI-BSCCO type H) was selected [17]. First the dependence of the critical current from the twist pitch was measured for a single tape. The twisting was applied at room temperature, and then the critical current measured at $77 \mathrm{~K}$ in self field. The results are plotted in fig. 8: the onset of the reduction in critical current is between $250 \mathrm{~mm}$ and $350 \mathrm{~mm}$. Therefore, for the construction of a first trial stacked strand, the twist pitch was set at $400 \mathrm{~mm}$. The twisted strand was prepared with a stack of 13 tapes, assembled and soldered between two copper profiles, resulting in a strand of $8 \mathrm{~mm}$ in diameter. The preparation was similar to the one discussed in section III.B.

The reduced critical current versus bending radius is plotted in fig. 9 for the twisted strand made with 13 DI-BSCCO tapes. In the same figure also the curve for the twisted strand made with REBCO tapes (used for the cable in section III) is also reported. The onset of the critical current reduction is located at a bending radius much longer than for the REBCO strands, mainly because of the low critical tensile strain of Bi2223 tapes $(0.25 \%)$, while in coated conductors it is about $0.6 \%$.

Once the number of strands in the cable is set, the cable twist pitch is proportional to the bending radius of the strand at the cable edge. Therefore for the Bi2223 cable a relative long twist pitch would be required (> $2000 \mathrm{~mm}$ ) because the

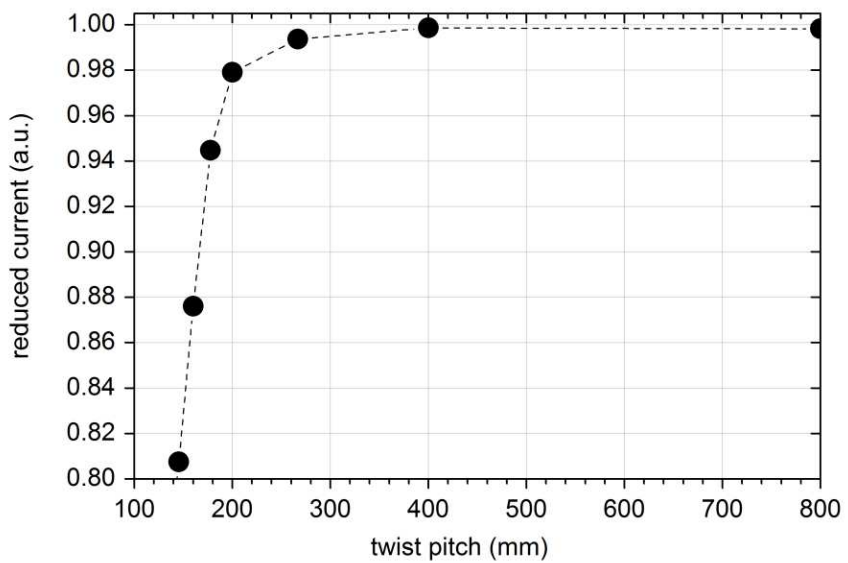

Fig. 8. Reduced critical current versus twist pitch for a DI-BSCCO tape type $\mathrm{H}$. The twist pitch was applied at room temperature.

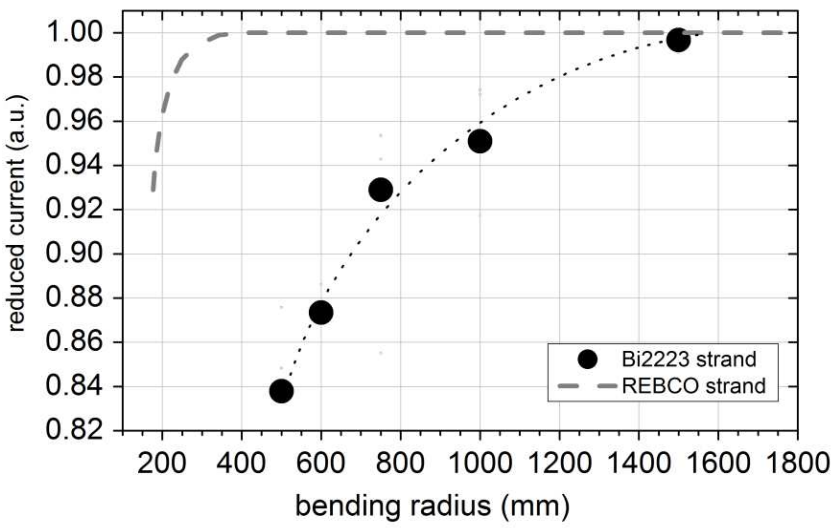

Fig. 9. Reduced critical current versus bending radius for the test strand ( $8 \mathrm{~mm}$ in diameter) made with 13 DI-BSCCO tapes. The dot line is a guide for the eye. The dashed line is for the $6.3 \mathrm{~mm}$ diameter strand, made with coated conductor tape, described in III (data are from [12]). 
strands can be bent only down to $1200 \mathrm{~mm} \sim 1500 \mathrm{~mm}$.

In order to achieve shorter cable twist pitches (i.e. shorter bending radius for the strand) it would be convenient to use Bi2223 laminated with steel (for example Sumitomo DI-BSCCO type HT), not because of the higher tensile strength, but because of the higher critical strain $(0.4 \%)$ due to the pre-compression from steel; the preparation of a stacked strand with reinforced tape is more complicated, because a low temperature melting point solder alloy should be used, in order to avoid melting the solder used for the lamination. Eventually pre-tensioned steel strips could be incorporated in the stack made of non-reinforced tapes. Another option, which is not available anymore from industry, is to use dispersion strengthened $\mathrm{AG} / \mathrm{Mg}$ alloy, which would also lead to higher critical strain.

Because of the large current capacity of the Bi2223 strands, a smaller number of strands is required than in the case of coated conductor tapes. Therefore it would be possible to arrange the strands around a circular copper core; the main advantage is that in a round cable a short cable twist pitch can be obtained even if the bending radius of the strands is relatively long.

\section{SUMMARY AND OUTLOOK}

The main activities at CRPP are focused on the development of fusion cables using coated conductors. In fact despite the continuous improvement in the engineering critical current density for all the HTS materials, coated conductor tape should be considered the most promising one, mainly because, being the newest arrived on the market, it has larger room for improvement, especially regarding low cost production. Moreover REBCO is the only HTS materials which can be potentially used at fields over $12 \mathrm{~T}$ and high temperature $(>30 \mathrm{~K})$. The design of a flat cable with twisted stacked strands, incorporating coated conductor tapes, was carried out. One prototype cable, about 2 meters long was manufactured and a second one is in preparation. The cable is composed of 20 strands, each containing 16 tapes $4 \mathrm{~mm}$ wide. The critical current of 7 strands out of 20 was measured before and after the cabling, and no reduction was observed. Extrapolating the values of the critical current measured on the tapes at $12 \mathrm{~T}$ and $4.2 \mathrm{~K}$, the critical current of the cable is expected to be about $60 \mathrm{kA}$, and the operating current could be between $50 \mathrm{kA}$ and $55 \mathrm{kA}$ with temperature margins of $6 \mathrm{~K}$ and $3 \mathrm{~K}$ respectively. A second cable section is now being manufactured; the two cables will be assembled in a sample which can be measured either in SULTAN or EDIPO facility. Relying on the accumulated experience, two cables (using coated conductor tapes) were designed for a DEMO class $(80 \mathrm{kA})$ magnet; test strands are in preparation.

The preliminary design of an $80 \mathrm{kA}$ cable made with Bi2212 wires has been carried out. The cable has an operating current of $80 \mathrm{kA}$ at $5 \mathrm{~K}$ and $13.5 \mathrm{~T}$, and it is suitable for a DEMO type fusion reactor.

The fabrication of a trial strand with $\mathrm{Bi} 2223$ tapes was completed, but the limited tensile strain of the Bi2223 tapes make the application more difficult than for coated conductor tapes.

Despite the technological challenges that should be overcome, the most important improvement before HTS materials could be applied in fusion magnets on large scale would be the decrease in the production cost, by at least an order of magnitude.

\section{ACKNOWLEDGMENT}

The authors thank the Paul Scherrer Institute (PSI) for the technical support.

\section{REFERENCES}

[1] P. Bruzzone, "Pre-conceptual studies and R\&D for DEMO superconducting magnets", Fusion Eng. Des., in press, DOI: 10.1016/j.fusengdes.2013.12.031

[2] P. Bruzzone, C. Sedlak, B. Stepanov, "High Current Superconductors for DEMO" Fusion Eng. Des. 2013, vol. 88, 1564-1568 http://dx.doi.org/10.1016/j.fusengdes.2012.12.004

[3] W. H. Fietz, et al. "Prospects of High Temperature Superconductors for fusion magnets and power applications" Fusion Eng. Des., 2013 http://dx.doi.org/10.1016/j.fusengdes.2013.03.059

[4] J. Zheng et al., "Concept design of hybrid superconducting magnet for CFETR Tokamak reactor", 2013 IEEE 25th Symposium on Fusion Engineering (SOFE), DOI: http://dx.doi.org/10.1109/SOFE.2013.6635364

[5] T. Ando et al., "Design of the toroidal field coil for A-SSTR2 using high Tc superconductor", Fusion Eng. Des., 2001, vol 58-59, 13-16.

[6] Y. Huang, H. Miao, S. Hong and J. A. Parrell, "Bi-2212 Round Wire Development for High Field Applications", IEEE Trans. Appl. Supercond., vol. 24, 2014, 6400205.

[7] T. Isono et al. "Development of $10 \mathrm{kA} \mathrm{Bi} 2212$ Conductor for Fusion Application", IEEE Trans. Appl. Supercond., vol. 13, 2003, 1512-1515.

[8] V. Lombardo, E. Barzi, D. Turrioni and A. V. Zlobin, "Critical Currents of $\mathrm{YBa}_{2} \mathrm{Cu}_{3} \mathrm{O}_{7-\delta}$ Tapes and $\mathrm{Bi}_{2} \mathrm{SrCa}_{2} \mathrm{Cu}_{2} \mathrm{O}_{\mathrm{x}}$ Wires at Different Temperatures and Magnetic Fields", IEEE Trans. Appl. Supercond., vol. 21, 2011, 3247-3250

[9] N. Cheggour, X. F. Lu, T. G. Holesinger, T. C. Stauffer, J. Jiang and L. F. Goodrich, "Reversible effect of strain on transport critical current in $\mathrm{Bi} 2 \mathrm{Sr} 2 \mathrm{CaCu} 2 \mathrm{O} 8+\mathrm{x}$ superconducting wires: a modified descriptive strain model", Supercond. Sci. Technol., vol. 25, 2012, 015001.

[10] D. R. Dietderich et al., "Critical Current Variation as a Function of Transverse Stress of Bi-2212 Rutherford Cables", IEEE Trans. Appl. Supercond., vol. 11, 2001, 3577-3579.

[11] M. Takayasu, L. Chiesa, L. Bromberg and J. V. Minervini, "HTS twisted stacked-tape cable conductor", Supercond. Sci. Technol., vol. 25, 2012, 014011.

[12] S. I. Schlachter, W. Goldacker, F. Grilli, R. Heller, and A. Kudymow, "Coated Conductor Rutherford Cables (CCRC) for High-Current Applications: Concept and Properties", IEEE Trans. Appl. Supercond., vol. 21, 2011, 3021-4.

[13] D. C. van der Laan, X. F. Lu, and L. F. Goodrich, "Compact $\mathrm{GdBa} 2 \mathrm{Cu} 3 \mathrm{O} 7-\delta$ coated conductor cables for electric power transmission and magnet applications", Supercond. Sci. Technol., vol. 24, 2011, 042001-4.

[14] C.E. Bruzek et al., "New HTS 2G Round Wires" IEEE Trans. Appl. Supercond., vol. 22, 2012, 5800204.

[15] D. Uglietti, R. Wesche and P. Bruzzone, "Design and Strand Tests of a Fusion Cable Composed of Coated Conductor Tapes", IEEE Trans. Appl. Supercond., vol. 24, 2014, 4800704.

[16] N. Bykovsky, D. Uglietti, R. Wesche, and P. Bruzzone, "Strain management in HTS high current cables", to be published in IEEE Trans. Appl. Supercond., vol. 22.

[17] T. Nakashima et al., "Overview of the recent performance of DI-BSCCO wire", Cryogenics, vol. 52, 2012, 713-718. 